\title{
Filmes finos nanoestruturados de dióxido de estanho obtidos pelo método dos precursores poliméricos
}

\section{Tin dioxide nanostructured thin films obtained through polymeric precursor method}

\author{
Marcelo Antônio Dal Santos ${ }^{1}$; Eder Carlos Ferreira de Souza ${ }^{2}$; André Vitor Chaves \\ de Andrade ${ }^{3}$; Christiane Philippini Ferreira Borges ${ }^{4}$; Sandra Regina Masetto \\ Antunes $^{5}$; Augusto Celso Antunes ${ }^{6}$
}

\begin{abstract}
Resumo
Filmes finos nanoestruturados de dióxido de estanho $\left(\mathrm{SnO}_{2}\right)$, com reduzida proporção de defeitos e com baixa rugosidade, foram produzidos a partir do controle da temperatura e da viscosidade das soluções precursoras durante a deposição dos filmes. As soluções foram obtidas pelo método dos citratos e os filmes foram depositados pela técnica "dip-coating" em substratos de vidro e tratadas termicamente a $470^{\circ} \mathrm{C} / 4 \mathrm{~h}$. Os filmes obtidos foram caracterizados estrutural e morfologicamente pelas técnicas de difratometria de raios $\mathrm{X}$, microscopia ótica, microscopia eletrônica de varredura, microscopia de força atômica, fluorescência de raios X, espectroscopia de absorção na região do UV-Vis e espectroscopia de fotoelétrons excitados por raios X. As espessuras dos filmes foram obtidas por microscopia eletrônica de varredura da seção transversal dos filmes e correlacionados com a proporção dos elementos Sn e Si obtida por fluorescência de raios X. A análise dos filmes por difratometria de raios X mostrou a presença de picos correspondente à fase cristalina cassiterita do $\mathrm{SnO}_{2}$, sobrepostos a um pico largo entre 20 e $30^{\circ}(2 \theta)$, característico do substrato de vidro. As microscopias ótica, eletrônica de varredura e de força atômica mostraram filmes homogêneos, com baixa rugosidade, adequados para diversas aplicações, como sensores e eletrodos transparentes. Pela análise por espectroscopia de absorção na região do UV-Vis, os filmes apresentaram alta transparência ótica e energia de "band gap" de 4,36 eV. Por espectroscopia de fotoelétrons excitados por raios X pode-se confirmar a presença de $\mathrm{SnO}_{2}$, bem como sinais dos elementos presentes no substrato de vidro e carbono residual proveniente do processo de tratamento térmico dos filmes.
\end{abstract}

Palavras-chave: Citratos. Pechini. $\mathrm{SnO}_{2}$. Deposição. Dip-Coating.

\begin{abstract}
Tin dioxide $\left(\mathrm{SnO}_{2)}\right.$ nanostructured thin films with low proportion of defects and low roughness were produced through the systematic control of temperature and viscosity of the precursor solutions used for thin films deposition. These solutions were obtained through the citrate method and the films were deposited through the 'dip-coating' technique on glass substrate and after thermal treatment at $470^{\circ} \mathrm{C} / 4 \mathrm{~h}$,
\end{abstract}

\footnotetext{
${ }^{1}$ Mestre em Engenharia e Ciência dos Materiais, Universidade Estadual de Ponta Grossa; msantos107@hotmail.com.

${ }^{2}$ Doutor em Química, PNPD/CAPES; Programa de Pós-Graduação em Química Aplicada da Universidade Estadual de Ponta Grossa; souza.eder@gmail.com.

${ }^{3}$ Docente do Departamento de Física da Universidade Estadual de Ponta Grossa; avcandrade@gmail.com.

${ }^{4}$ Docente do Departamento de Química da Universidade Estadual de Ponta Grossa; cpfborges@uol.com.br.

${ }^{5}$ Docente do Departamento de Química da Universidade Estadual de Ponta Grossa; sr-antunes@bol.com.br.

${ }^{6}$ Docente do Departamento de Química da Universidade Estadual de Ponta Grossa; augusto.celso@pq.cnpq.br.
} 
they were characterized both structurally and morphologically through the X-ray diffractometry, optic microscopy, scanning electronic microscopy, atomic force microscopy, X-ray fluorescence, UV-Vis absorption spectroscopy and X-ray excited photoelectrons spectroscopy. The film thickness was obtained through scanning electronic microscopy of the films cross-section and correlated to the proportion of $\mathrm{Sn}$ and Si obtained through X-ray fluorescence. X-ray diffractometry of the films revealed the presence of peaks corresponding to the $\mathrm{SnO}_{2}$ crystalline phase, overlapping a wide peak between 20 and $30^{\circ}(2 \theta)$, characteristic of the glass substrate. Optic microscopy, Scanning electronic microscopy and atomic force microscopy revealed homogeneous films, with low roughness, suitable to several applications such as sensors and transparent electrodes. It could be observed through the UV-Vis absorption analysis that the films presented high optical transparency and 'band gap' energy $4.36 \mathrm{eV}$. The X-ray excited photoelectron spectroscopy confirmed the presence of $\mathrm{SnO}_{2}$, as well as traces of the elements present in the glass substrate and residual carbon from the thermal treatment of the films.

Key words: Citrates. Pechini. $\mathrm{SnO}_{2}$. Deposition. Dip-Coating.

\section{Introdução}

O dióxido de estanho $\left(\mathrm{SnO}_{2}\right)$ vem sendo utilizado em um grande número de aplicações tecnológicas, especialmente em sensores, catalisadores, dispositivos eletro-ópticos e células fotovoltaicas (KIM et al., 2011), (GROSSMANN et al., 2011), (KOCEMBA; RYNKOWSKI, 2011), (LI et al., 2011), (BENHEBAL et al., 2011), (KARSHOGLU; UYSAL; AKBULUT, 2011), (OSHIMA; TAKEMOTO; YOSHINO, 2011), (PAN; LI, 2011), (YOSHIDA et al., 2008).

Isso se deve a algumas de suas propriedades, tais como alta condutividade elétrica, alta estabilidade térmica, mecânica e química e, quando na forma de filme fino, alta transparência ótica na região do visível.

Os métodos de preparação de dióxido de estanho são amplamente estudados com o intuito de melhorar as propriedades físico-químicas dos materiais obtidos. Entre os métodos mais empregados, podem-se citar: sol-gel, condensação de fase gasosa, "spray"-pirólise, microemulsão, rotas hidrotérmicas, entre outras. Um método que vem sendo bastante utilizado para obtenção de nanopartículas de dióxido de estanho puro ou dopado é o método dos citratos (PECHINI, 1967). O método dos citratos recebeu atenção considerável por possibilitar a obtenção de óxidos com alto controle estequiométrico a partir de soluções poliméricas com grande homogeneidade em nível atômico. Além disso, produz pós nanométricos, que tornam o sistema cerâmico muito atrativo para a criação de novos materiais funcionais, cujas propriedades dependem do tamanho de partícula. O método dos citratos pode ser utilizado tanto na obtenção de pós como de filmes de dióxido de estanho.

Filmes finos e espessos à base de dióxido de estanho são muito utilizados na produção de sensores. Entretanto, a seletividade e a sensibilidade desses sensores dependem do método de síntese da solução precursora, da técnica de deposição de filmes empregada, bem como do substrato utilizado.

No presente trabalho, foram estudadas as propriedades físico-químicas, morfológicas e estruturais de filmes de dióxido de estanho. Visando obter filmes livres de trincas e com baixa rugosidade, foram realizadas deposições de filmes a partir de soluções com diferentes viscosidades, mantendo-se a temperatura da solução constante. As soluções precursoras foram obtidas pelo método dos citratos (Pechini) e os filmes foram depositados em substratos de vidro pela técnica "dip-coating".

\section{Procedimento Experimental}

Para obtenção da solução precursora usada na 
deposição dos filmes finos, partiu-se de uma solução aquosa de ácido cítrico mono-hidratado (4 mol), etileno-glicol (16 mol) e tartarato de estanho II (1 mol). Algumas gotas de ácido nítrico concentrado foram adicionadas para completar a dissolução dos reagentes. O processo de polimerização da solução foi realizado com aquecimento $\left(80^{\circ} \mathrm{C}\right)$ sob agitação constante resultando em uma resina polimérica com alta viscosidade. O tartarato de estanho II usado neste estudo foi previamente preparado pela reação entre ácido tartárico e cloreto de estanho II (SANTOS et al., 2000).

Uma vez obtida a solução precursora (resina polimérica), a proporção de $\mathrm{SnO}_{2}$ em função do volume e da massa de resina foi analisada por gravimetria.

As viscosidades das soluções precursoras foram determinadas com o auxílio de um Reômetro BROOKFIELD - DV-II+ equipado com "spindle" $n^{\circ} 27$. A temperatura das soluções foi mantida em $40{ }^{\circ} \mathrm{C}$ e suas viscosidades foram ajustadas para 500 , 350 e $200 \mathrm{cP}$ através de diluição com água.

Após a obtenção e caracterização das soluções precursoras, os filmes foram depositados pela técnica "dip-coating" em substratos de vidro CORNING 2947 previamente limpos. As soluções precursoras foram mantidas na temperatura desejada $\left(40{ }^{\circ} \mathrm{C}\right)$ por meio de banho de aquecimento.

O processo "dip-coating" consiste na imersão e emersão de um substrato numa solução precursora contendo o material a ser depositado. Após a imersão, o substrato foi retirado da solução (emersão), carregando uma camada de filme líquido sobre sua superfície. A fim de evitar irregularidades na superfície do filme depositado, como resultado de um deslizamento não homogêneo da camada de filme líquido aderida sobre a superfície, é de extrema importância o controle da velocidade de imersão/emersão do substrato. A espessura do filme foi controlada repetindo-se o processo de imersão/ emersão do substrato na solução e posterior secagem do filme amorfo.
Os parâmetros de deposição dos filmes foram fixados em:

- $\quad$ temperatura da solução precursora: $40{ }^{\circ} \mathrm{C}$;

- viscosidades das soluções precursoras: 200,350 e $500 \mathrm{cP}$.

- velocidade de imersão/emersão do substrato na solução precursora: $3 \mathrm{~cm} / \mathrm{min}$;

- $\quad$ secagem dos filmes amorfos em estufa: 140 ${ }^{\circ} \mathrm{C} / 30 \mathrm{~min}$;

- $\quad$ número de deposições da solução precursora em substrato de vidro: 4 camadas.

O tratamento térmico dos filmes amorfos obtidos foi realizado em forno tipo mufla. A taxa de aquecimento foi de $1{ }^{\circ} \mathrm{C} / \mathrm{min}$, até a temperatura de $470{ }^{\circ} \mathrm{C}$, permanecendo nessa temperatura por 4 h. Após esse tempo, o forno foi resfriado até temperatura ambiente com uma taxa de resfriamento de $1{ }^{\circ} \mathrm{C} / \mathrm{min}$. Um fluxo constante de ar comprimido $(0,2 \mathrm{~L} / \mathrm{min})$ foi utilizado para auxiliar na queima da matéria orgânica, proveniente da degradação da solução precursora durante o tratamento térmico.

Os filmes tratados termicamente foram caracterizados por difração de raios X (DRX) para determinação das fases presentes e avaliação do grau de cristalinidade das mesmas. As medidas de difratometria de raios $\mathrm{X}$ com ângulo rasante de incidência foram realizadas em um equipamento SHIMADZU - XRD 6000, equipado com acessório para medidas de filmes, modelo THA-1101, com rotação de amostra na faixa de $1 \mathrm{a} 60 \mathrm{rpm}$. Utilizouse um comprimento de onda médio de 1,5406 $\AA\left(\mathrm{K}_{\alpha \mathrm{Cu}}\right)$, ângulo fixo de incidência $\theta$ de $1,5^{\circ} \mathrm{e}$ varredura em $2 \theta$ de 20 a $60^{\circ}$.

A superfície dos filmes foi observada por microscopia ótica utilizando um microscópio LEICA, modelo Mz26 e fotografadas por uma câmara CCD KODO Digital KC 512. O equipamento MEV utilizado foi o SHIMADZU - SS 550. Foram analisadas a superfície e a seção transversal dos filmes previamente metalizados com ouro. 
Para avaliar um método alternativo de determinação de espessuras dos filmes obtidos, foram realizadas análises de fluorescência de raios $\mathrm{X}$ (FRX), com determinação dos teores de elemento $\mathrm{Si}$ (componente do substrato) e de elemento $\mathrm{Sn}$ (componente do filme). O equipamento utilizado foi o LEICA CAMBRIDGE - Stereoscan 440.

A microscopia de força atômica (AFM) foi utilizada para verificar a rugosidade superficial dos filmes, a qual afeta a resposta ótica dos filmes na região do UV-Vis. O equipamento utilizado foi o microscópio SHIMADZU - SPM 9500 J33.

Através de medidas de espectroscopia de absorção da região do UV-Vis analisou-se a homogeneidade dos filmes e determinaram-se as energias relacionadas à transições eletrônicas e, indiretamente, foi obtido o índice de refração dos filmes. O equipamento utilizado foi um espectrofotômetro UV-Vis VARIAN - Cary 100, de duplo feixe com acessório móvel para realização da análise em diferentes pontos da amostra e "software" de coleta de dados "VARIAN SCAN".

Para a análise de espectroscopia fotoeletrônica de raios X (XPS), utilizou-se um equipamento VG MICROTECH - Multilab Esca 3000, com fonte de $\mathrm{MgK} \alpha$, com potência de 1.253,6 eV, resolução de $0,8 \mathrm{eV}$ e pressão de $10^{-10}$ mbar.

\section{Resultados e Discussão}

$\mathrm{Na}$ deposição de filmes finos a viscosidade é um parâmetro crítico, pois influencia diretamente na espessura dos filmes obtidos, afetando a sua microestrutura e propriedades óticas. Além disso, espessuras elevadas induzem à formação de trincas no filme durante o tratamento térmico.

$\mathrm{Na}$ Figura 1, está apresentado os valores da viscosidade em função da taxa de cisalhamento da solução precursora em duas temperaturas, observase que a viscosidade mantem-se constante com o aumento da taxa de cisalhamento.
Figura 1 - Viscosidades da solução precursora em função da taxa de cisalhamento nas temperaturas de 25 e $40{ }^{\circ} \mathrm{C}$.

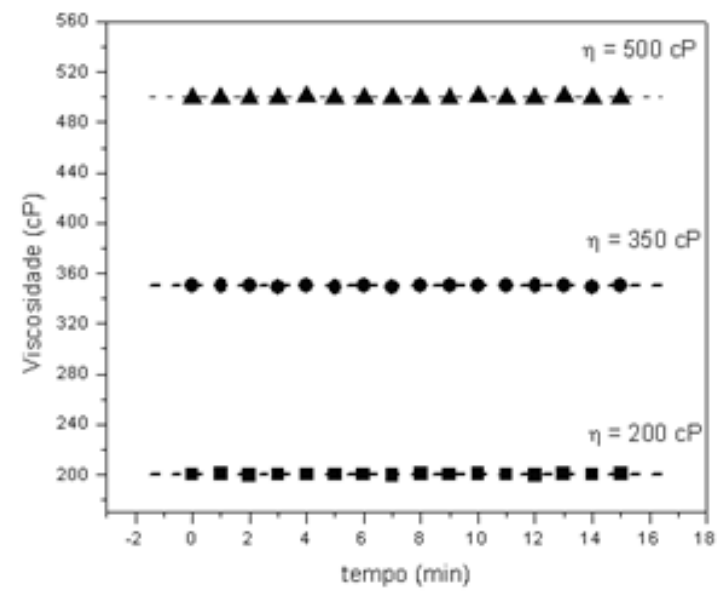

Fonte: Dados do autor

Como esperado, o aumento da temperatura de $25{ }^{\circ} \mathrm{C}$ para $40{ }^{\circ} \mathrm{C}$ provoca uma diminuição da viscosidade das soluções. Porém, mesmo a $40{ }^{\circ} \mathrm{C}$, o valor de viscosidade é considerado elevado, quando se trata da obtenção de filmes finos. Portanto, foram realizadas diluições em água a temperatura $40{ }^{\circ} \mathrm{C}$ e os resultados encontram-se na Figura 2.

Figura 2 - Viscosidades das soluções precursoras em diferentes diluições com água, em função do tempo. A temperatura das soluções para esta análise foi mantida em $40{ }^{\circ} \mathrm{C}$.

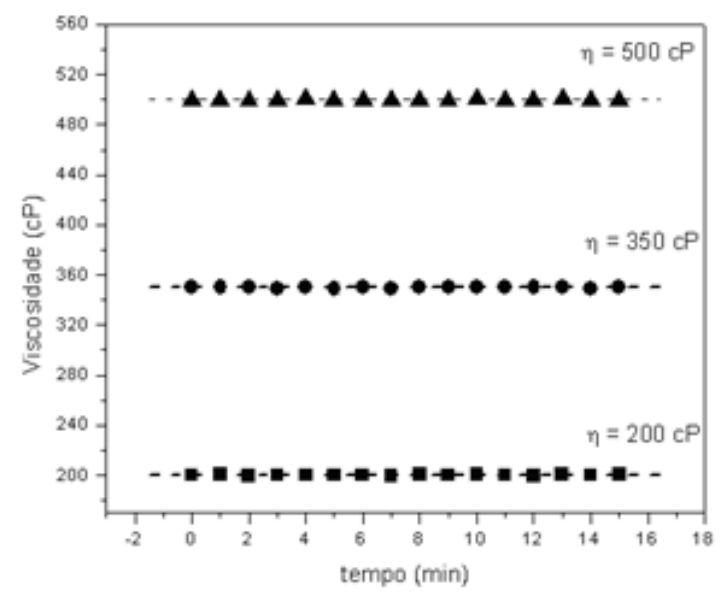

Fonte: Dados do autor. 
Os resultados de viscosidade apresentados sugerem que as soluções precursoras usadas para a deposição dos filmes apresentam comportamento newtoniano, ou seja, a viscosidade é independente da taxa de cisalhamento (força aplicada tangencialmente à superfície do fluido) e do tempo (RODRIGUES; OLIVI, 2003).

Através de micrografias obtidas por microscopias ótica e eletrônica de varredura (MEV), foi possível observar a homogeneidade superficial dos filmes e a morfologia dos grãos. Nas Figuras 3, 4 e 5, estão apresentadas as micrografias ótica dos filmes de $\mathrm{SnO}_{2}$, obtidos a partir de soluções precursoras com diferentes viscosidades (200, 350 e 500 cP). Como se pode observar nas Figuras, os filmes obtidos a partir de soluções com viscosidade acima de $200 \mathrm{cP}$ apresentam grande quantidade de defeitos, prejudicando suas propriedades morfológicas e óticas.

Visando minimizar o surgimento de defeitos nos filmes, para as demais caracterizações, utilizou-se a solução precursora com viscosidade de $200 \mathrm{cP}$ na temperatura de $40^{\circ} \mathrm{C}$ para a deposição dos filmes pelo processo "dip-coating".

Na Figura 6, são apresentadas micrografias obtidas por microscopia eletrônica de varredura dos filmes de $\mathrm{SnO}_{2}$ com 4 camadas.

Figura 3 - Micrografia ótica dos filmes de $\mathrm{SnO}_{2}$ com 4 camadas, depositados em substratos de vidro e tratados termicamente a $470{ }^{\circ} \mathrm{C} / 4 \mathrm{~h}$. Viscosidade da solução precursora $200 \mathrm{cP}$.

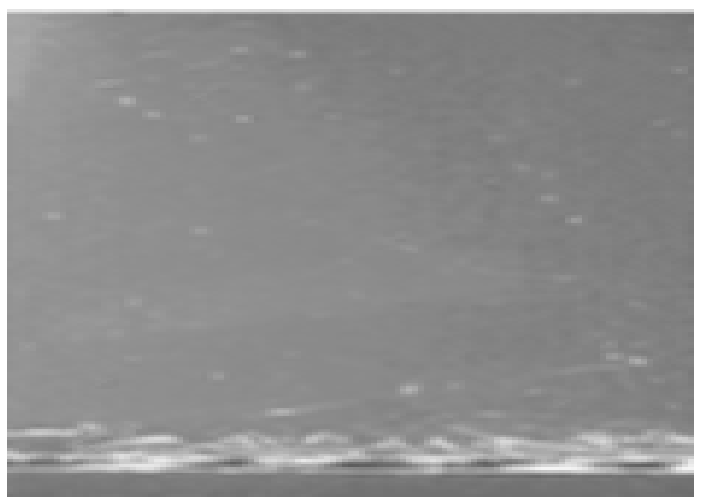

Fonte: Dados do autor.
Figura 4 - Micrografia ótica dos filmes de $\mathrm{SnO}_{2}$ com 4 camadas, depositados em substratos de vidro e tratados termicamente a $470{ }^{\circ} \mathrm{C} / 4 \mathrm{~h}$. Viscosidade da solução precursora $350 \mathrm{cP}$.

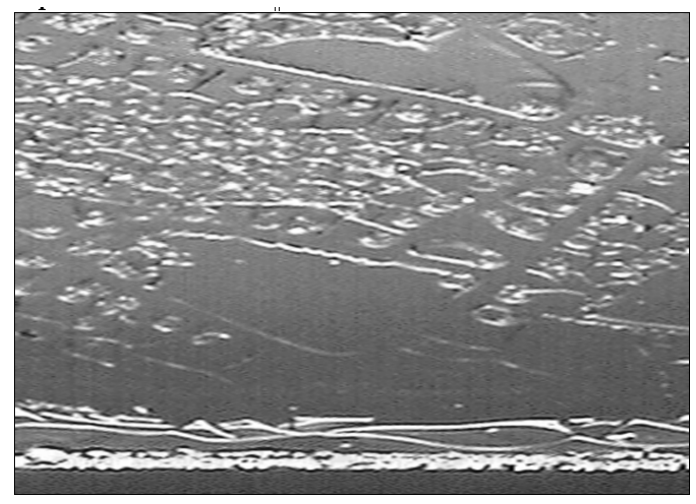

Fonte: Dados do autor.

Figura 5 - Micrografia ótica dos filmes de $\mathrm{SnO}_{2}$ com 4 camadas, depositados em substratos de vidro e tratados termicamente a $470{ }^{\circ} \mathrm{C} / 4 \mathrm{~h}$. Viscosidade da solução precursora $500 \mathrm{cP}$.

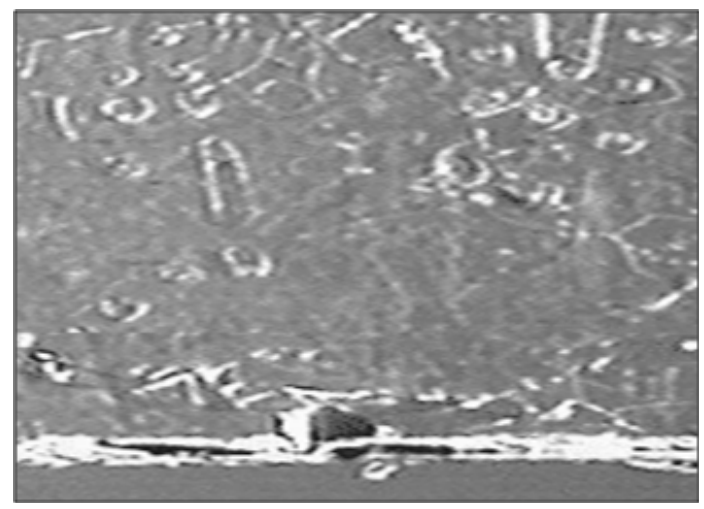

Fonte: Dados do autor

A micrografia mostrada na Figura 6 indica que há uma distribuição homogênea dos grãos de $\mathrm{SnO}_{2}$ em toda a extensão do filme. Contudo, nas regiões próximas às bordas do substrato, foram observadas algumas imperfeições, originadas durante o tratamento térmico dos filmes pela tensão mecânica entre o filme depositado e o substrato. Essa tensão é proveniente da dilatação superficial desigual, devido aos diferentes coeficientes de expansão térmica do filme e do substrato (SHAMALA et al., 2004). 
Figura 6 - Micrografia obtida por MEV dos filmes de $\mathrm{SnO}_{2}$ com 4 camadas, depositados em substratos de vidro a partir de soluções precursoras com viscosidade de $200 \mathrm{cP}$ e tratados termicamente a $470{ }^{\circ} \mathrm{C} / 4 \mathrm{~h}$.

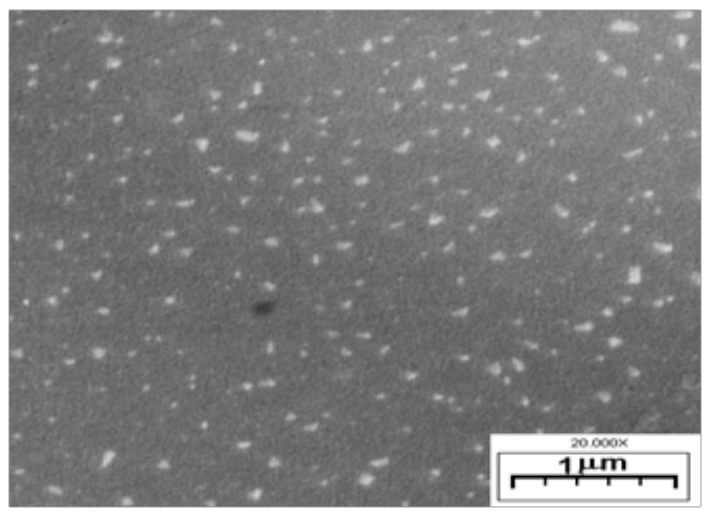

Fonte: Dados do autor.

As espessuras dos filmes de $\mathrm{SnO}_{2}$ foram determinadas por MEV, a partir das micrografias obtidas da seção transversal dos filmes, utilizando o "software" que acompanha o microscópio para realizar as medidas de espessura. Para avaliar um método alternativo de medidas de espessuras de filmes, utilizou-se a combinação das técnicas de fluorescência de raios $X$ (FRX) e microscopia eletrônica de varredura (MEV), como sugerido por (ZANETTI et al., 1996).

Após o tratamento térmico, os filmes foram analisados por FRX e as proporções dos elementos Sn (componente do filme) e Si (componente do substrato) foram determinadas. Assim, podese determinar exclusivamente o sinal referente ao filme fino $\left(\mathrm{SnO}_{2}\right)$, descontando-se o sinal do substrato $\left(\mathrm{SiO}_{2}\right)$. Os mesmos filmes utilizados para as medidas de fluorescência de raios $\mathrm{X}$ foram cortados de modo a obter-se sua seção transversal para medidas da espessura, utilizando-se o MEV operando no modo de elétrons retroespalhados, onde se pode distinguir entre o substrato e o filme pela diferença de contraste. Uma das micrografias obtidas por MEV usadas para medidas da espessura dos filmes é apresentada na Figura 7.
Os resultados das medidas de espessura dos filmes obtidos por MEV foram correlacionados com as intensidades dos elementos Sn e Si obtidos por FRX, obtendo-se as curvas de calibração para estanho e silício. A curva obtida para o elemento estanho está apresentada na Figura 8. A equação de ajuste obtida foi $\mathrm{y}=0,097+6,09 \cdot 10^{-5} \cdot \mathrm{x}$, com $\mathrm{R}^{2}$ $=0,993$.

Figura 7 - Micrografia obtida por MEV para medidas de espessura dos filmes de $\mathrm{SnO}_{2}$ com 4 camadas, depositados em substrato de vidro a partir de soluções precursoras com viscosidade de $200 \mathrm{cP}$ e tratados termicamente a $470{ }^{\circ} \mathrm{C} / 4 \mathrm{~h}$.

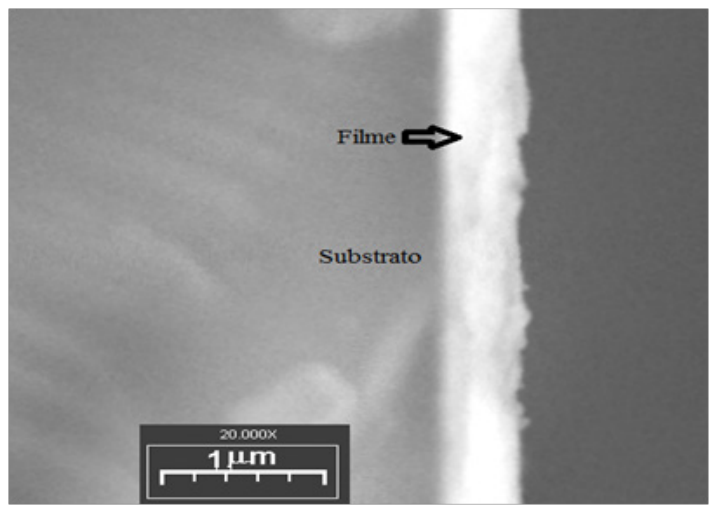

Fonte: Dados do autor.

Na Tabela 1, encontram-se as médias dos valores de espessuras de vários filmes finos com 4 camadas, obtidos a partir de soluções precursoras com viscosidade de $200 \mathrm{cP}$. Os valores referentes à fluorescência de raios X são a média das espessuras calculadas a partir da curva de calibração de cada elemento analisado. Analisando-se a Tabela 1 , observa-se que as duas técnicas empregadas forneceram medidas de espessuras com boa concordância, podendo o método de FRX ser utilizado para medir espessuras de filmes finos com boa precisão, desde que a curva de calibração já tenha sido previamente obtida. Observa-se também que a espessura média dos filmes está em torno de $400 \mathrm{~nm}$, sendo esse valor bem inferior ao limite de $1 \mu \mathrm{m}$, característico de filmes finos. 
Figura 8 - Gráfico da intensidade obtida por fluorescência de raios X para o elemento estanho em função da espessura dos filmes medida por MEV.

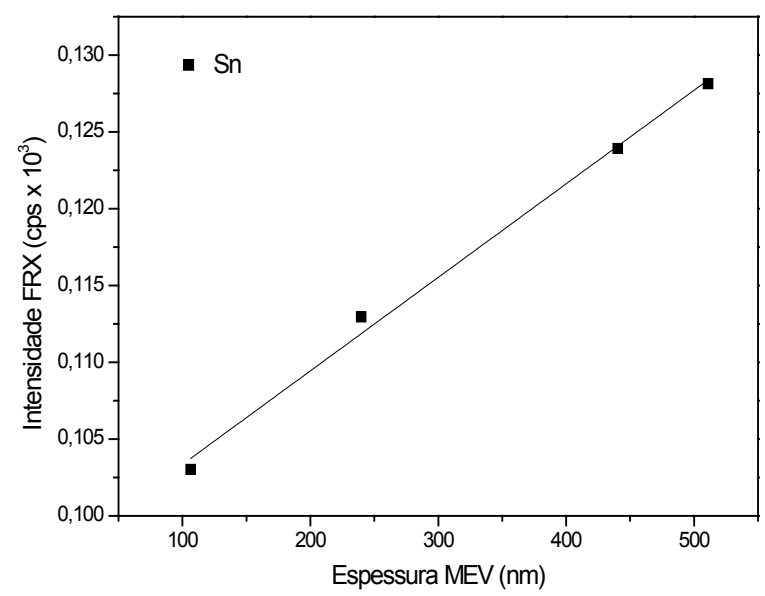

Fonte: Dados do autor.

Tabela 1 - Espessuras obtidas diretamente por MEV e calculadas a partir das intensidades de FRX para os filmes de $\mathrm{SnO}_{2}$ com 4 camadas, depositados em substrato de vidro a partir de soluções precursoras com viscosidade de $200 \mathrm{cP}$ e tratados termicamente a $470{ }^{\circ} \mathrm{C} / 4 \mathrm{~h}$.

\begin{tabular}{ccc}
\hline Filmes & $\begin{array}{c}\text { Espessura - MEV } \\
(\mathrm{nm})\end{array}$ & $\begin{array}{c}\text { Espessura - FRX } \\
(\mathrm{nm})\end{array}$ \\
\hline 4 camadas & 440 & 407 \\
\hline
\end{tabular}

Fonte: Dados do autor.

Para avaliar a morfologia superficial dos filmes, foram realizadas análises por microscopia de força atômica dos filmes. Na Figura 9, apresentase a micrografia obtida por microscopia de força atômica (MFA) dos filmes de $\mathrm{SnO}_{2}$ com 4 camadas, depositados em substratos de vidro a partir de soluções precursoras com viscosidade de $200 \mathrm{cP}$ e tratados termicamente a $470{ }^{\circ} \mathrm{C} / 4 \mathrm{~h}$.
Analisando-se a Figura 9, pode-se observar a morfologia tridimensional dos aglomerados de partículas de $\mathrm{SnO}_{2}$ sobre a superfície dos filmes. Nota-se que o filme apresenta baixa rugosidade média. Esta rugosidade pode influenciar as propriedades óticas do material, como discutido a seguir nos resultados das medidas de espectroscopia de absorção na região do UV-Vis. A técnica analisa apenas uma pequena área superficial $(1,7 \times 1,7 \mu \mathrm{m})$ referente ao topo dos filmes, não sendo possível distinguir todas as camadas que compõem o filme, sendo por isso não indicada para medidas de espessuras. Por isso, devem ser utilizadas outras técnicas como MEV e FRX, entre outras.

Figura 9 - Micrografia obtida por microscopia de força atômica (MFA) dos filmes de $\mathrm{SnO}_{2}$ com 4 camadas, depositados em substrato de vidro a partir de soluções precursoras com viscosidade de $200 \mathrm{cP}$ e tratados termicamente a $470{ }^{\circ} \mathrm{C}$ por $4 \mathrm{~h}$.

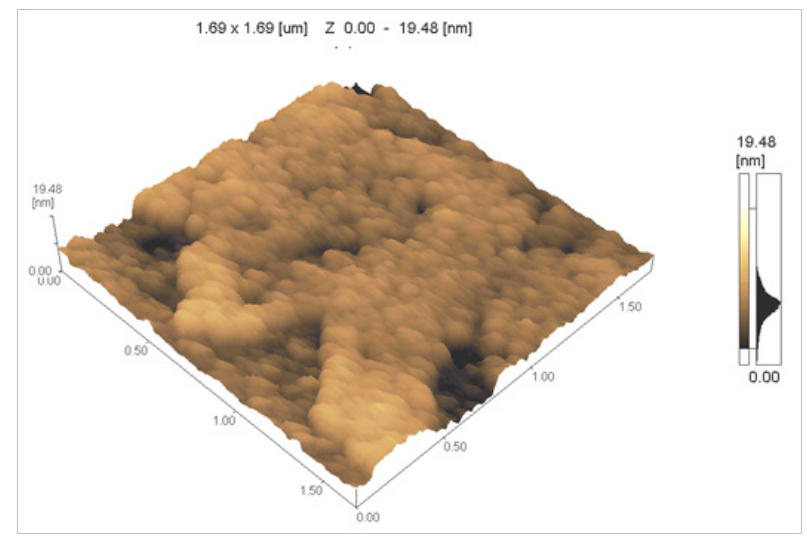

Fonte: Dados do autor.

$\mathrm{Na}$ Figura 10, apresenta-se o difratograma de raios $\mathrm{X}$ dos filmes de $\mathrm{SnO}_{2}$ com 4 camadas, depositados em substratos de vidro a partir de soluções precursoras com viscosidade de $200 \mathrm{cP}$ e tratados termicamente a $470{ }^{\circ} \mathrm{C} / 4 \mathrm{~h}$.

Pela análise dos difratogramas de raios $\mathrm{X}$ pode- 
se observar os picos de difração referentes à fase cassiterita do $\mathrm{SnO}_{2}$ sobrepostos ao pico largo de material amorfo relacionado ao substrato de vidro utilizado na deposição dos filmes. Os picos detectados coincidem com a ficha JCPDF 41-1445, correspondente ao $\mathrm{SnO}_{2}$ tetragonal, com estrutura rutilo.

Figura 10 - Difratograma de raios $\mathrm{X}$ dos filmes de $\mathrm{SnO}_{2}$ com 4 camadas, depositados em substratos de vidro a partir de soluções precursoras com viscosidade de $200 \mathrm{cP}$ e tratados termicamente a $470{ }^{\circ} \mathrm{C} / 4 \mathrm{~h}$.

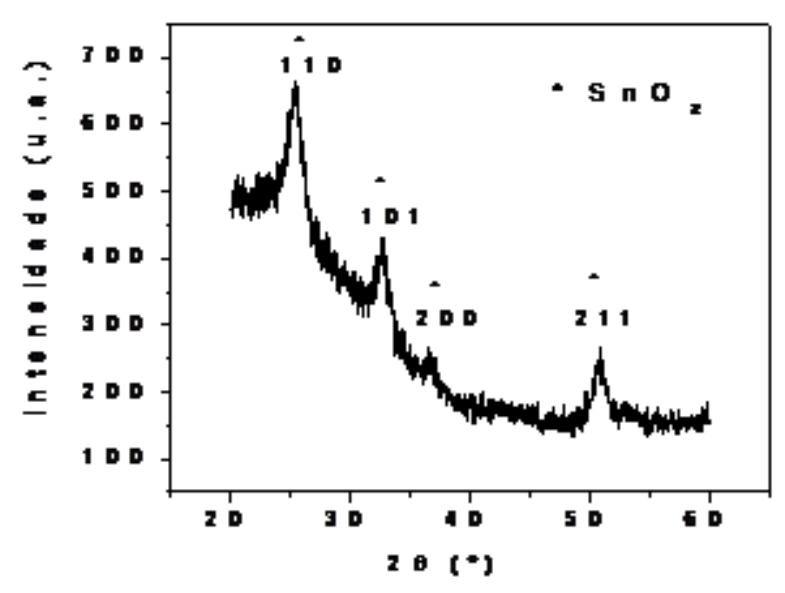

Fonte: Dados do autor.

Através de medidas de espectroscopia de absorção da região do UV-Vis, analisou-se a homogeneidade dos filmes, observando-se a presença ou ausência de franjas de interferências. A partir dos valores médios de transmissão ótica obtidos nessas medidas, podese determinar indiretamente o índice de refração dos filmes. A Figura 11 apresenta os espectros obtidos para os filmes de $\mathrm{SnO}_{2}$ com 4 camadas, depositados em substratos de vidro. As medidas foram realizadas em diferentes posições de cada amostra, buscandose obter valores médios da resposta ótica de cada composição.

Pode-se observar, na Figura 11, que valores de transmitância ótica da ordem de $80 \%$ para comprimentos de onda acima de $380 \mathrm{~nm}$ foram obtidos para os filmes estudados. A forte absorção observada na região do ultravioleta próximo $(\lambda<$ $350 \mathrm{~nm}$ ) é típica de transição interbanda (valênciacondução) em semicondutores de banda larga.

Observa-se que os filmes não apresentam flutuações nas curvas de transmitância, que são denominadas de franjas de interferência. Esse fato sugere que os filmes obtidos apresentam as camadas superficiais homogêneas, sem falhas ao longo dos filmes (defeitos) que interfiram na passagem de luz (transmissão e reflexão). Para minimizar os possíveis efeitos de variação de espessura ao longo da extensão dos filmes, foram realizadas medidas em diferentes pontos da amostra. Pode-se verificar, contudo, que os espectros obtidos para os filmes praticamente se sobrepõem, indicando que esses apresentam homogeneidade ao longo da região analisada, característica imprescindível para certas aplicações óticas de filmes. O índice de refração determinado a partir dos dados obtidos das curvas de transmitância foi de 2,195.

Figura 11 - Espectros obtidos por espectroscopia de absorção na região do UV-Vis, para os filmes de $\mathrm{SnO}_{2}$ com 4 camadas, depositados em substrato de vidro a partir de soluções precursoras com viscosidade de $200 \mathrm{cP}$ e tratados termicamente a $470{ }^{\circ} \mathrm{C} / 4 \mathrm{~h}$. Os valores de $\mathrm{P}$ referem-se à posição linear do filme onde foi executada a medida.

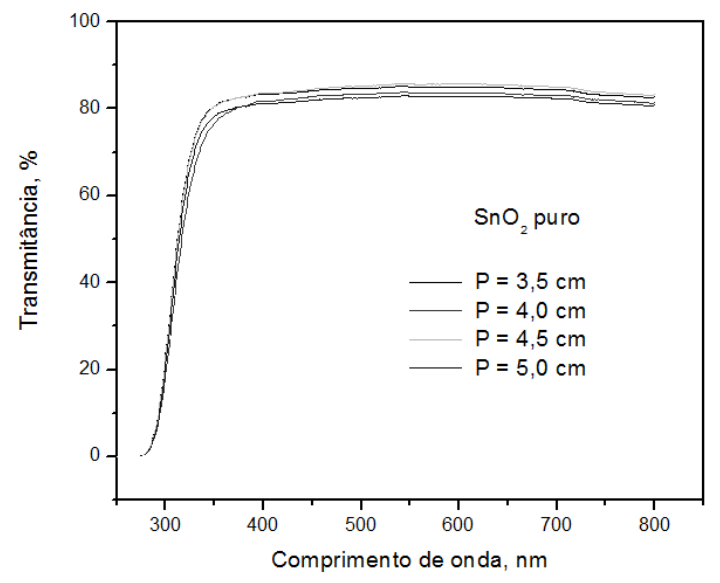

Fonte: Dados do autor. 
Os valores do "band gap" de energia (transição direta) dos filmes foram determinados a partir dos espectros de UV-Vis dos filmes. As energias relacionadas a transições eletrônicas ("band gap") foram determinadas a partir dos gráficos de $(\alpha h v)^{2}$ em função de hv, onde $\alpha$ é o coeficiente de absorção ótica.

O "band gap" de energia foi obtido pela extrapolação (Figura 12) da curva de $(\alpha h v)^{2}$ em função da energia de excitação $(h v)$ até a interceptação do eixo das abscissas, usando regressão linear pelo método dos mínimos quadrados com $\mathrm{R}^{2} \geq 0,95$. O valor do "band gap" de energia obtido para os filmes de $\mathrm{SnO}_{2}(4,36$ $\mathrm{eV}$ ) encontra-se em concordância com os dados encontrados na literatura (NASSER, 1999).

$\mathrm{Na}$ Figura 13, pode-se observar o espectro de fotoelétrons excitados por raios X (XPS) obtido da superfície dos filmes de $\mathrm{SnO}_{2}$ com 4 camadas. A análise quantitativa dos elementos presentes nos filmes depositados no substrato de vidro foi realizada a partir das intensidades dos picos.

Analisando-se o espectro apresentado na Figura 13, pode-se verificar que foram detectados os elementos Sn e O presentes no filme, bem como os sinais dos elementos $\mathrm{Si}$ e $\mathrm{Na}$, referentes ao substrato de vidro. O sinal do elemento $\mathrm{C}$ devese ao resíduo de matéria orgânica do processo de decomposição do precursor polimérico durante o tratamento térmico do filme. Para a identificação dos elementos presentes na superfície dos filmes utilizaram-se valores de referência das energias de ligação dos elementos puros e dos seus principais óxidos e compostos mostrados na Tabela 2 (MOULDER et al., 1993).

Figura 12 - Gráfico de $(\alpha h v)^{2}$ em função da energia de excitação (hv) para determinação do "band gap" de energia (transição direta) dos filmes de $\mathrm{SnO}_{2}$ com 4 camadas, depositados em substrato de vidro a partir de soluções precursoras com viscosidade de $200 \mathrm{cP}$ e tratados termicamente a $470{ }^{\circ} \mathrm{C}$ por $4 \mathrm{~h}$.

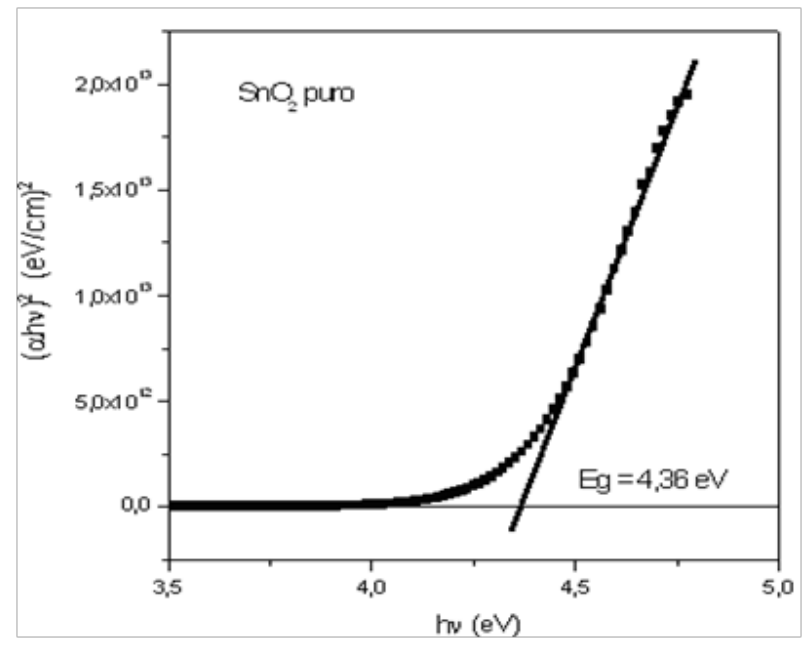

Fonte: Dados do autor.

Figura 13 - Espectro de fotoelétrons excitados por raios X (XPS) da superfície dos filmes de $\mathrm{SnO}_{2}$ com 4 camadas, depositados em substrato de vidro a partir de soluções precursoras com viscosidade de $200 \mathrm{cP}$ e tratados termicamente a $470{ }^{\circ} \mathrm{C} / 4 \mathrm{~h}$.

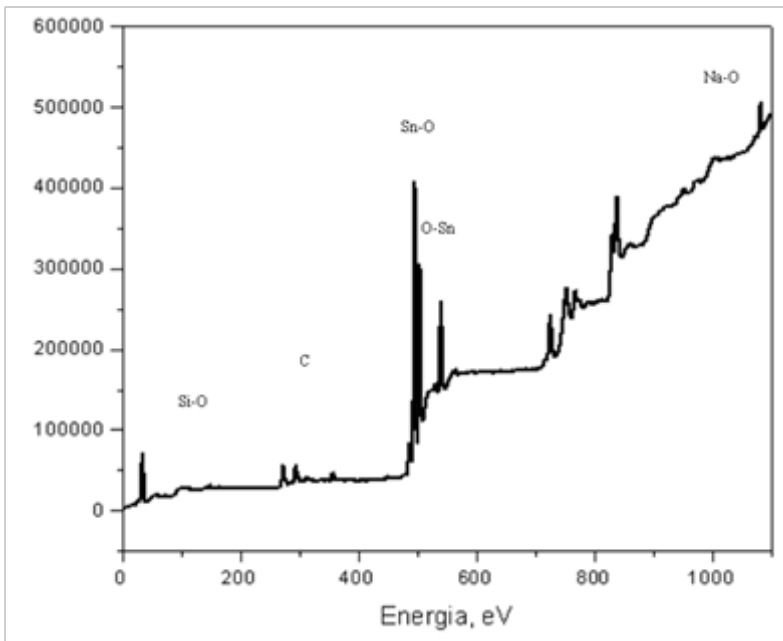

Fonte: Dados do autor. 
A Tabela 2 relaciona os principais sinais de fotoemissão dos elementos detectados nos filmes de $\mathrm{SnO}_{2}$ depositados em substrato de vidro.

Tabela 2 - Principais sinais de fotoemissão e energias de ligação para os elementos detectados nos filmes de $\mathrm{SnO}_{2}$ depositados em substrato de vidro.

\begin{tabular}{cccccc}
\hline Elementos & $\mathrm{Si}$ & $\mathrm{C}$ & $\mathrm{Sn}$ & $\mathrm{O}$ & $\mathrm{Na}$ \\
\hline $\begin{array}{c}\text { Principal sinal } \\
\text { XPS }\end{array}$ & $2 \mathrm{p3}$ & $1 \mathrm{~s}$ & $3 \mathrm{~d} 5 / 3 \mathrm{~d} 3$ & $1 \mathrm{~s}$ & $1 \mathrm{~s}$ \\
$\begin{array}{c}\text { Compostos } \\
\text { mais comuns }\end{array}$ & $\mathrm{SiO}_{2}$ & $\begin{array}{c}\mathrm{C} \\
\text { grafite }\end{array}$ & $\mathrm{SnO}_{2}$ & $\mathrm{SnO}_{2}$ & $\mathrm{Na}_{2} \mathrm{O}$ \\
$\begin{array}{c}\text { Energias de } \\
\text { ligação }(\mathrm{eV})\end{array}$ & $(103,0)$ & $(284,5)$ & $(487,3)$ & $(530,6)$ & $(1072,0)$ \\
\hline
\end{tabular}

Fonte: Dados do autor.

\section{Conclusões}

Pela análise dos resultados obtidos, podemos concluir que é possível obter filmes finos nanoestruturados de $\mathrm{SnO}_{2}$ a partir de soluções preparadas pelo método dos precursores poliméricos (Pechini). O estudo realizado durante o ajuste reológico da solução precursora (resina polimérica) permitiu determinar a viscosidade de $200 \mathrm{cP}$ e temperatura de $40{ }^{\circ} \mathrm{C}$ como parâmetros ideais da solução precursora para a deposição de filmes de $\mathrm{SnO} 2$ livres de defeitos em sua superfície. A análise dos filmes por DRX mostrou a presença de picos correspondentes à fase cristalina cassiterita do $\mathrm{SnO}_{2}$, sobreposto um pico largo entre 20 e $30^{\circ}$ $(2 \theta)$, característico de material amorfo relacionado ao substrato de vidro. As microscopias ótica, eletrônica de varredura e de força atômica mostraram filmes homogêneos, com poucos defeitos e baixa rugosidade, adequados para diversas aplicações, como sensores e eletrodos transparentes. Os filmes apresentaram altas transparência ótica na região do UV-Vis e energia de "band gap" de 4,36 eV. Por XPS, pode-se confirmar a presença da fase $\mathrm{SnO}_{2}$, bem como sinais dos elementos presentes no substrato de vidro e carbono residual proveniente do processo de tratamento térmico dos filmes.

\section{Agradecimentos}

Os autores agradecem o suporte financeiro concedido pela Capes/PNPD, pelo CNPq e pela Fundação Araucária - Paraná.

\section{Referências}

BENHEBAL, H.; CHAIB, M.; LEONARD, A.; LAMBERT, S. D.; CRINE, M. Synthesis, characterization and photocatalytic properties of alkali metals doped tin dioxide. Journal of Molecular Structure, Amsterdam, v. 1004, n. 1-3, p. 222-226, 2011.

GROSSMANN, K.; KOVACS, K. E.; PHAM, D. K.; MAEDLER, L.; BARSAN, N.; WEIMAR, U. Enhancing performance of FSP $\mathrm{SnO}_{2}$-based gas sensors through $\mathrm{Sb}$ doping and Pd-functionalization. Sensors and Actuators B - Chemical, Lausanne, v. 158, n. 1, p. 388-392, 2011.

KARSHOGLU, R.; UYSAL, M.; AKBULUT, H. The effect of substrate temperature on the electrical and optic properties of nanocrystalline tin oxide coatings produced by APCVD. Journal of Crystal Growth, Amsterdam, v. 327, n. 1, p. 22-26, 2011.

KIM, H. R.; HAENSCH, A.; KIM, I. D.; BARSAN, N.; WEIMAR, U.; LEE, J. H. The role of NiO doping in reducing the impact of humidity on the performance of $\mathrm{SnO}_{2}$-based gas sensors: synthesis strategies, and phenomenological and spectroscopic studies. Advanced Functional Materials, Weinheim, v. 21, n. 23, p. 44564463, 2011.

KOCEMBA, I.; RYNKOWSKI, J. The influence of catalytic activity on the response of $\mathrm{Pt} / \mathrm{SnO}_{2}$ gas sensors to carbon monoxide and hydrogen. Sensors and Actuators $B$ - Chemical, Lausanne, v. 155, n. 2, p. 659-666, 2011.

LI, W.; SHEN, C.; WU, G.; MA, Y.; GAO, Z.; XIA, 
X.; DU, G. New model for a Pd-doped $\mathrm{SnO}_{2}$-based $\mathrm{CO}$ gas sensor and catalyst studied by online in-Situ X-ray Photoelectron Spectroscopy. Journal of Physical Chemistry C, Washington, v. 115, n. 43, p. 21258-21263, 2011.

MOULDER, J. F.; STICKLE, W. F.; SOBOL, P. E.; BOMBEN, K. D. Handbook of X-ray Photoelectron Spectroscopy. Eden Prairie: Physical Electronics, 1993.

NASSER, S. A. Characterization of boron-doped tin oxide thin films. Thin Solid Films, Lausanne, v. 342, n. 1-2, p. 47-51, 1999.

OSHIMA, M.; TAKEMOTO, Y.; YOSHINO, K. Optical and electrical characterization of FTO films grown by spray-pyrolysis method. Physica Status Solidi $C$, Warsaw, v. 6, n. 5, p. 1124-1126, 2011.

PAN, S.; LI, G. Recent progress in p-Type doping and optical properties of $\mathrm{SnO}_{2}$ nanostructures for optoelectronic device applications. Recent Patents on Nanotechnology, Sharjah, v. 5, n. 2, p. 138-161, 2011.

PECHINI, M. P. Method of preparing lead and alkaline earth titanates and niobates and coating method using the same to form a capacitor, U.S. Patent No. 3.330.697, Alexandria, 1967.

RODRIGUES, E. C. P. E.; OLIVI, P. Preparation and characterization of $\mathrm{Sb}$-doped $\mathrm{SnO}_{2}$ films with controlled stoichiometry from polymeric precursors. Journal of Physics and Chemistry of Solids, New York, v. 64, n. 7, p. 1105-1112, 2003.

SANTOS, R. D.; ANTUNES, A. C.; ANTUNES, S. R. M.; PIANARO, S. A.; LONGO, E.; VARELA, J. A. Preparação de dióxido de estanho via decomposição de organometálicos. Publicatio, Ponta Grossa, v. 6, n. 1, p. 91-101, 2000.

SHAMALA, K. S.; MURTHY, L. C. S.; RAO, K. N. Studies on tin oxide films prepared by electron beam evaporation and spray- pyrolysis methods. Bulletin of Materials Science, New York, v. 27, n. 3, p. 295-301, 2004.

YOSHIDA, Y.; TOKASHIKI, S.; KUBOTA, K.; SHIRATUCHI, R.; YAMAGUCHI, Y.; KONO, M.; HAYASE, S. Increase in photovoltaic performances of Dye-Sensitized Solar Cells - Modification of interface between $\mathrm{TiO}_{2}$ nano-porous layers and F-doped $\mathrm{SnO}_{2}$ layers. Solar Energy Materials and Solar Cells, Amsterdam, v. 92, n. 6, p. 646-650, 2008.

ZANETTI, S. M.; FOSCHINI, C. R.; LEITE, E. R.; LONGO, E.; VARELA, J. A.; OLIVI, P. A fluorescência de raios $X$ aplicada á determinação da espessura de filmes finos de PZT. Cerâmica, São Paulo, v. 42, n. 275, p. 99-102, 1996.
Recebido em 9 Abril 2012-Received on April 9, 2012. Aceito em 25 Julho, 2012 - Accepted on July 25, 2012. 
